\title{
Correspondence
}

The Royal College of Nursing (Ren) code of conduct

SIR,

The text, discussion and commentary upon The 'Royal College of Nursing (RCN) code of conduct' has, I feel, left one point of major significance overlooked. I refer to the disparity between the parenthetical statement in the discussion of section II paragraph 4 , and the full import of phraseology for the equivalent section in the text. The phrases 'unnecessary treatments' and 'hazardous experimental procedures' surely have far wider implications than the sole issue of indirect (or passive) euthanasia cited as an example in the discussion. Consider whether it would be 'unnecessary' to operate on a patient to remove the cause of ill health where the symptoms could be alleviated by drugs, or whether it is a "hazardous experimental procedure' to employ a new treatment where no other form of treatment can be guaranteed to succeed. The answer would presumably be that it depends upon all the circumstances in each case. But do nurses really wish to take it upon themselves to become the arbiters of what is and is not 'unnecessary' or 'experimental' ? Clearly, a case conference would not place the nurse in the position of being the only person to make the decision, but there remain attendant dangers here. The most radical concept of such a conference, that of a group of people without an acknowledged leader caring for a patient, may be likened to that of an army without effective generals or a school without an effective head: where the buck stops, he or she it is that has to 'carry the can'. This point is particularly relevant when it is necessary to make a split-second decision, for example, to resuscitate or not to resuscitate. Somebody has to make the choice, and the whole team must be ready to assist unquestionably.

The Bill of Rights (I689) included such vague terms as "cruel and unusual punishments'. However, that Bill aimed to set right past grievances and it did not merely produce instrumentally good effects by creating the conditions whereby a workable settlement could be achieved, but it was also related to the past in such a way that people (not simply the politicians) could

extrapolate from the abstract form $\overrightarrow{\mathrm{m}}$ lary to a concrete instance. The Rch document would not be so clearco ordinary people, and I fear thas a lack of confidence would follow the code found its way into tbe hands of people who were unawire of the high professional standarids of nurses.

In practice, I very much doust that problems have arisen since November last, or that they will arise. I hope not. Few nurges would, I suspect, wish to invole themselves in an equal responstbility for a patient with a doctornot least in terms of legal culyability. Neither do I think that a nurse would wish to question the consultant's treatment - although perhaps that of a junior doctor. \&f these last assumptions are accuraze, then the effect of section II, pagagraph 4 of the code would appearato be pragmatically innocuous - bit the theoretical danger of the wordi ought not to be overlooked. MARTYN BER⿳⺈⿴囗十 Coventity

\section{Death, Dying and the Biological Revolution}

Robert Veatch

Yale University Press, London, 1976

As a sincere and intense look at the problems raised by our new ability to prolong the process of dying, this book is a valuable contribution to thought for the very small number of people interested enough to plough through it.

Robert Veatch has a deep mistrust of doctors. This is a shame because had he discussed the manuscript with a medical friend, some of his misunderstandings could have beeh avoided. At the outset he ove estimates medical power in dealing with infections. The assumption thit everyone in future will die $8 f$ degenerative diseases reflects a rather cocky scientific view of maross 